\title{
Intelligent Integrated Model for Improving Performance in Power Plants
}

\author{
Ahmed Ali Ajmi ${ }^{1,2}$, Noor Shakir Mahmood ${ }^{1,2}$, Khairur Rijal Jamaludin ${ }^{1, *}$, \\ Hayati Habibah Abdul Talib ${ }^{1}$, Shamsul Sarip ${ }^{1}$ and Hazilah Mad Kaidi ${ }^{1}$
}

\author{
${ }^{1}$ Razak Faculty of Technology and Informatics, UTM, 54100, Kuala Lumpur, Malaysia \\ ${ }^{2}$ University of Technology, Ministry of Electricity GCEP/Middle Region Baghdad, Iraq \\ ${ }^{*}$ Corresponding Author: Khairur Rijal Jamaludin. Email: khairur.k1@utm.my \\ Received: 18 July 2021; Accepted: 19 August 2021
}

\begin{abstract}
Industry 4.0 is expected to play a crucial role in improving energy management and personnel performance in power plants. Poor performance problem in maintaining power plants is the result of both human errors, human factors and the poor implementation of automation in energy management. This problem can potentially be solved using artificial intelligence (AI) and an integrated management system (IMS). This article investigates the current challenges to improving personnel and energy management performance in power plants, identifies the critical success factors (CSFs) for an integrated intelligent framework, and develops an intelligent framework that enables power plants to improve performance. The theoretical basis is founded on a systematic literature review to locate 110 out of 3108 papers studied carefully to examine the performance architecture that best enables effective maintenance. The findings from this literature review are combined with expert judgment and the big data advantages of AI applications to develop an intelligent model. Data are collected from a power plant in Iraq. To ensure the reliability of the proposed model, various hypotheses are tested using structural equation modeling. The results confirm that the measurement model is acceptable, and that the hypotheses are supported and significant. A case study demonstrates the strong relationship and significance between big data of performance and the CSFs. It is hoped that this model will be adopted to enable performance improvement in power plants.
\end{abstract}

Keywords: Industry 4.0; artificial intelligence; critical success factors; decision making; integrated management system; maintenance

\section{Introduction}

Performance in the maintenance of power plant facilities often poses significant risks. To address the consequences of human errors, it is necessary to focus on the human factors related to these risks [1]. Artificial intelligence (AI), integrated management system (IMS) and the Internet of Things can help improve performance toward the vision of Industry 4.0 in power plants, which anticipates advanced levels of automated performance [2]. Industry 4.0 is intended to integrate performance within power plants, thus reducing human errors and ensuring high energy

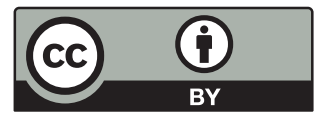

This work is licensed under a Creative Commons Attribution 4.0 International License, which permits unrestricted use, distribution, and reproduction in any medium, provided the original work is properly cited. 
efficiency [3]. Lack of intelligent integration of performance and poor automation in the maintenance of power plants causes losses that are roughly 2.5 times higher than those attributed to hardware failure [4]. In terms of maintenance, personnel performance is closely related to energy management performance, and is thus a factor in energy consumption and human errors [5,6], although further investigation is required to determine the interaction between personnel, energy management, and the critical success factors (CSFs) associated with thermal and gas power plant maintenance [7].

To date, most previous studies dealing with improvements to performance have focused on nuclear power plants. Relatively few studies have analyzed the performance in the maintenance of thermal and gas power plants and the associated effects on the reliability of the power generation system. Using a systematic literature review (SLR), this study identifies the existing problems and challenges facing performance in power plants. This SLR investigates several studies using modern technologies and categorizes them based on their focus and findings. The previous literature dealing with the interaction between personnel performance and energy management performance in maintaining power plants is analyzed in an attempt to answer three specific research questions: (RQ1) What are the current challenges facing the improvement of performance in the maintenance of power plants? (RQ2) What are the CSFs for integrating an intelligent performance improvement framework? (RQ3) Is it possible to develop an intelligent framework that can improve performance? This study provides a new vision for improving performance based on Industry 4.0 and AI, clarifying the integration of personal performance with energy management performance in gas and thermal power plants within an intelligent framework. To achieve this, 110 studies from five reliable databases are analyzed. Using the results of this analysis, an intelligent framework for performance integration is then developed, along with the judgment of experts working in power plants. To the best of our knowledge, this is the first study to collect and organize existing evidence in order to develop an intelligent framework. The proposed framework will assist power plants in overcoming poor performance, reducing human errors, and enhancing energy management.

\section{Methodology}

Great efforts were made to address the scarcity of data. To enhance the SLR, a framework was constructed based on the Industry 4.0 vision. The object of this study was a power plant in Iraq. Most power plants in Iraq are old and have complex performance and energy management problems, making them suitable for such studies. A two-way approach was adopted in which information from energy experts and power plant specialists was used in the development stage to increase reliability. The aim of the study was to systematically investigate the CSFs for improving performance in power plants under the Industry 4.0 vision. Fig. 1 illustrates the complete methodology of the SLR. 


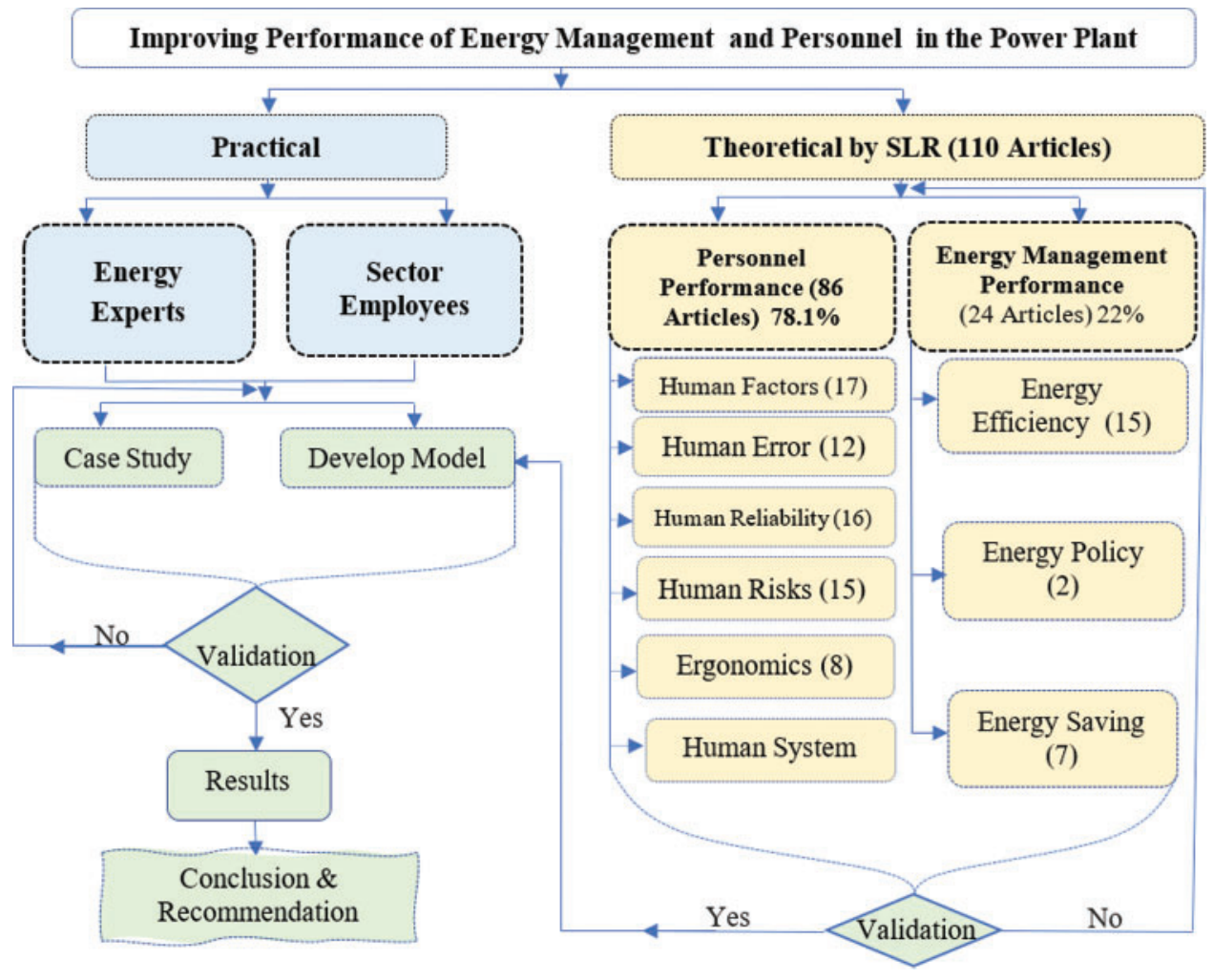

Figure 1: Research methodology flowchart

\subsection{Quality Assessment}

To ensure the quality of the SLR and reduce the possibility of bias, the selected articles were screened and filtered using a three-step process. First, the selected papers were scanned to identify their general content and eliminate duplicates. Second, the articles were examined in more detail (abstracts and conclusions), and those failing to meet the predetermined criteria were excluded. Third, the papers were read thoroughly, at which point we attempted to emulate the authors' work. This phase allows the novelty, strengths, and weaknesses of an article to be identified. This stage further excluded articles that did not meet the needs of the present study. For reference management, EndNote X9 was used to classify, sort, and delete duplicate articles. Finally, the Newcastle Ottawa Scale (NOS) assessed the quality of the remaining literature. The quality assessment was conducted by three of the authors independently, and a fourth reviewer resolved any disagreements.

\subsection{Study Protocol and Criteria}

The study developed a protocol and a set of stringent criteria for analyzing published studies and discover the patterns of existing research to help us identify research gaps. The research adopted a clearly defined, rigorous, and reliable approach that allows presenting objective and reproducible results to reduce possible bias. Study criteria include i) articles written in English only; ii) focused specifically on discussing or investigating the performance of energy management and personnel. Fig. 2 shown the criteria and steps used to identify the literature to be included in the analysis. 


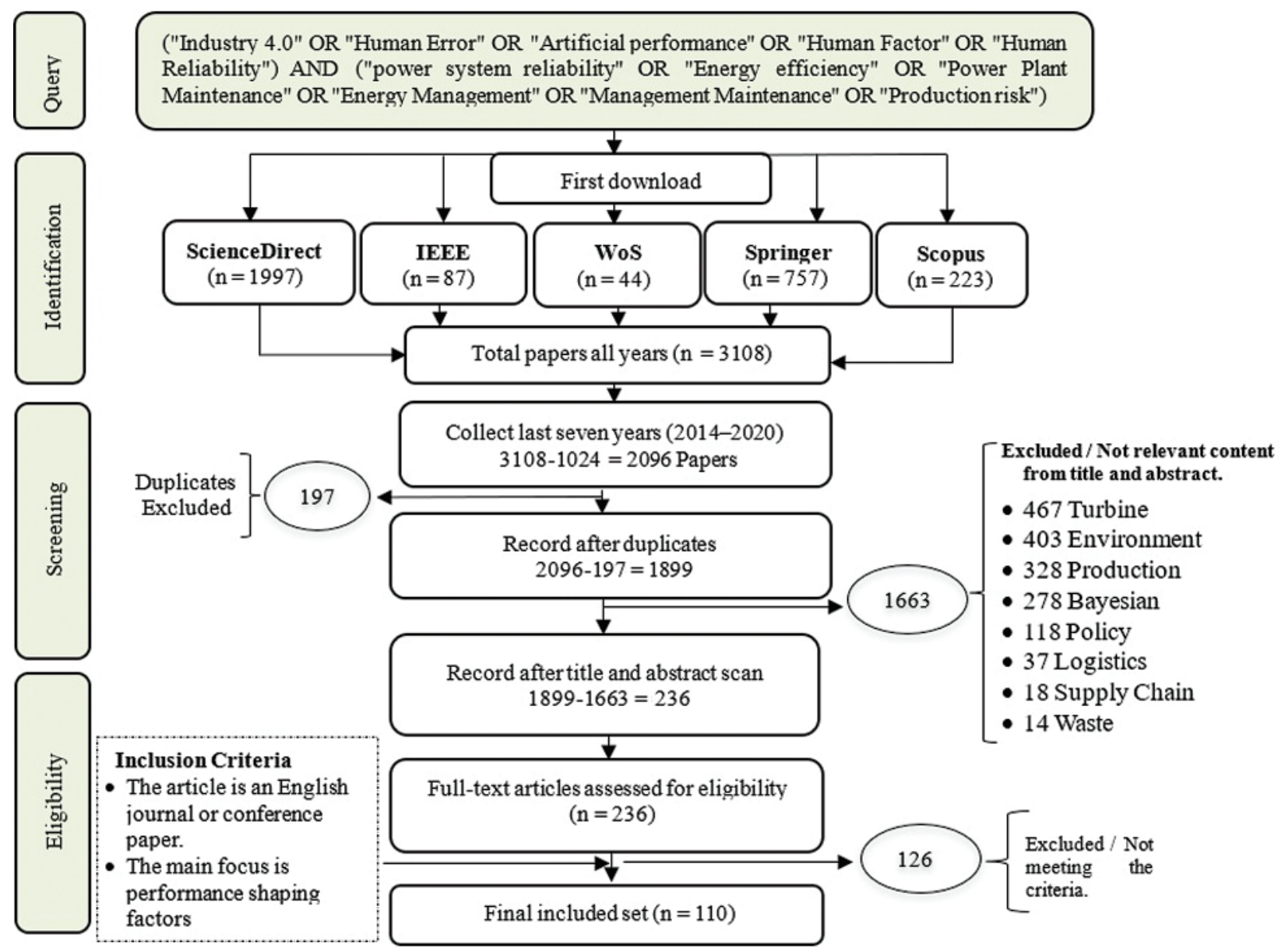

Figure 2: Steps in identifying the literature included in the analysis

\section{Results of SLR}

The initial search located 3108 articles. Of these, 1997 were sourced from ScienceDirect, 87 were from IEEE Xplore, 44 were from Web of Science, 757 were from Springer Link, and 223 were from Scopus. All articles were published between 2014 and 2020. Accessibility issues prevented us from downloading three papers from Web of Science and two papers from Springer Link. The selected papers were filtered based on the research sequence described in the previous section: 197 papers that appeared in all five search engines were excluded, and the remaining articles were examined in further detail. Finally, 110 articles were considered relevant to the present study.

\subsection{Analysis of the Performance Shaping Factors Architecture in Industry 4.0}

The 110 articles remaining after the three-step filtering process can be categorized into two classes: (i) personnel performance and (ii) energy management performance.

\subsubsection{Human Factors}

Human factors should not be overlooked, as they play a key role in ensuring the stability of maintenance procedures. Indeed, both the culture of maintenance and employee performance are essential variables in improving human factors [8,9]. Meta-analysis of human factors could 
help improve employee performance in power plants [10]. Similarly, human factors have been analyzed in terms of the risks faced by thermal power plants' maintenance staff [11]. This analysis showed that, to minimize such errors, understanding human behavior is imperative. Apart from staff behavior, another cause of poor performance is fatigue, time stress, work overload, and lack of teamwork [12-14]. It has been suggested that optimizing maintenance schedules can reduce work overload [15]. Other articles focused on current and future human factors related to interactions between different management decision-making processes [16-19]. It has been reported that interest in human factors in maintenance and operation can be considered one of the tools for the digital transformation of the industry, improving employee reliability [20-22]. Finally, human performance fundamentally affects power system operation reliability [23].

\subsubsection{Human Error}

Human errors in power plant maintenance increase the percentage of dangerous accidents, production delays, and losses of money and time [24]. The effects of human errors on power systems have been analyzed [25-27], and the factors causing human errors in power systems have been classified using statistical methods [28,29]. Case studies have attempted to measure the human errors in power plants in an attempt to form a cognitive, systemic mechanism to minimize such errors [30,31]. Based on two case studies and questionnaires, a Bayesian network has been used to develop a human error probability model [32]. Human errors significantly affect power system operations, and so a modified evaluation models of power system reliability have been developed by integrating human efforts with protection system failures [33-35].

\subsubsection{Energy Management Performance in Industry 4.0}

We now focus on issues, technologies, and case studies related to employee performance and energy management practices in maintenance and operation activities. This section investigates and examines the available empirical evidence to clarify the relationship between employee performance and energy management. Two case studies [36,37] investigated employee factors related to energy efficiency and energy reduction in factories through semi-structured interviews. The results indicated a strong relationship between employee performance and energy efficiency. Another study [38] developed a framework that enables human-centric energy efficiency to be enhanced, so that interactions between personnel and assets that consume energy can be improved. Four other articles [39-42] investigated the role of workers in raising energy efficiency in the workplace. Interpretive structural modeling has been used to show that human factors and the workplace environment play an important role in energy management [43,44]. The challenges and benefits of implementing energy management in a factory were analyzed in [45], which recommended adopting energy management within maintenance processes. Reference [46] presented several interdisciplinary concepts relating to human performance interaction for energy efficacy, whilst [47-49] investigated how the support and leadership style of top management figures influenced decision-making regarding improvements in maintenance energy efficiency. The effect of personnel performance roles on energy policy research has been studied [50,51], and a new model-based assessment of industrial workers' behavior in relation to energy saving social factors and personnel training has been utilized to save energy in maintenance tasks [52,53]. Human performance is vital in enhancing energy management during maintenance by controlling exactly when equipment is shut down and started up [54-61]. Improve the interaction between performance shaping factor with energy management performance is important in industry 4.0 with more attention in CSFs such as skill flexibility, commitment, motivation, energy policy, continuous 
improvement and top management support [62-66]. Fig. 3 refers to the current literature trends in energy management performance based on our literature review.

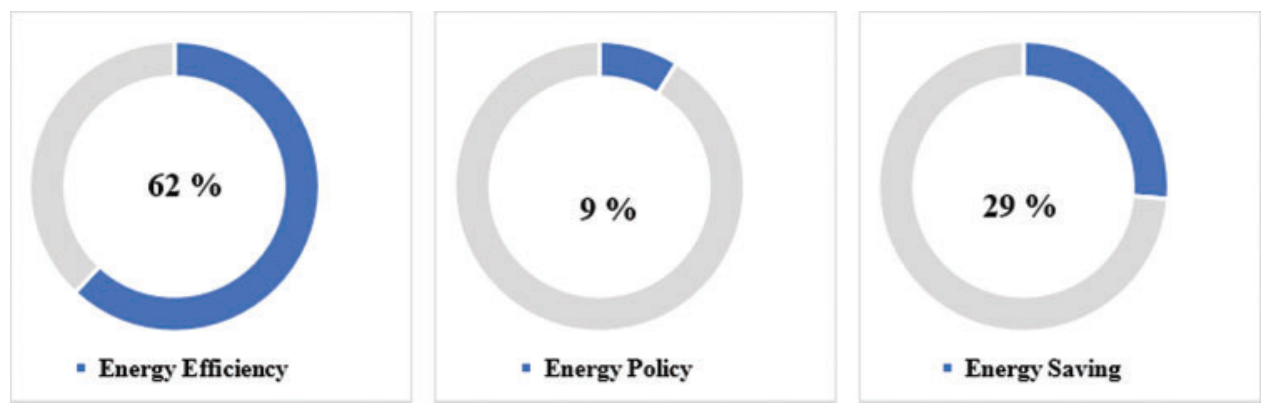

Figure 3: Current trends in energy management performance

\subsection{Success Indicators of Integration Performance for Personnel and Energy Management}

A careful study of the previous literature has identified the most important indicators for the successful integration of personnel performance with energy management performance in power plants. The CSFs help power plants to attain their goals. The most important CSFs identified by previous studies are listed in Tab. 1. The CSFs are maintenance culture (MC) or Leadership practice (LP), teamwork (TE), skill flexibility (SF), commitment (CO), motivation (M), time pressure (TP), awareness (A), work overload (WO), top management support (TMS), energy efficiency (EE), energy policy (EP), and continuous improvement (CI).

This study investigates the integration between CSFs for personnel performance and CSFs for energy management performance. The goal of this analysis is to reduce human errors and improve human factors in the workplace, thus optimizing maintenance performance in power plants. Fig. 4 illustrates the contribution of various indicators of success for any integration between performance elements.

\subsection{Results of SLR}

\subsubsection{Distribution by Publication Year}

In Fig. 5, the articles analyzed in the SLR are grouped according to year of publication. For each year in the period 2014-2020, the articles were broken down according to whether they focus on performance reliability or energy management.

\subsubsection{Distribution by Nationality}

Fig. 6 shows that authors from 41 countries published reports relating to reliability and performance in the maintenance during the period 2014-2020. The nationality distribution of 110 technology-related papers in numbers and showed that the main contributors are from the United States (27), followed by China (18); Germany (10); United Kingdom (9); South Korea (8); Australia (7); Iran (6); Brazil, France, and Italy (5 each); Belgium, India, and Norway (4 each); Canada, Malaysia, Denmark and Sweden (3 each); Turkey, Belgium, Netherlands, Poland, Romania, and Spain (2 each); Argentina, Belgrade, Colombia, Czech Republic, Finland, Indonesia, Ireland, New Zealand, Pakistan, Russian, Saudi Arabia, Scotland, Slovakia, South Africa, Georgia, Slovenia, Japan and Algeria (1 each). 
Table 1: Comparison of performance integration success indicators

\begin{tabular}{|c|c|c|c|c|c|c|c|c|c|c|c|c|}
\hline \multirow[t]{2}{*}{ Study } & \multicolumn{12}{|c|}{ Main area } \\
\hline & $\mathrm{LP}$ & $\mathrm{TE}$ & SF & $\mathrm{CO}$ & $\mathrm{M}$ & $\mathrm{TP}$ & A & WO & TMS & $\mathrm{EE}$ & EP & $\mathrm{CI}$ \\
\hline [6-9] & $\checkmark$ & $\checkmark$ & $\checkmark$ & $\checkmark$ & $\checkmark$ & & $\checkmark$ & $\checkmark$ & & $\checkmark$ & & \\
\hline [10] & & & $\checkmark$ & & & & & & & & & \\
\hline [11] & $\checkmark$ & & $\checkmark$ & & & $\checkmark$ & $\checkmark$ & $\checkmark$ & & & & $\checkmark$ \\
\hline [12-14] & & $\checkmark$ & $\checkmark$ & $\checkmark$ & $\checkmark$ & $\checkmark$ & & $\checkmark$ & & $\checkmark$ & & \\
\hline [15] & & & & $\checkmark$ & & $\checkmark$ & & $\checkmark$ & & & & \\
\hline [17] & & $\checkmark$ & $\checkmark$ & $\checkmark$ & $\checkmark$ & & $\checkmark$ & & & & & \\
\hline$[18,19]$ & $\checkmark$ & & $\checkmark$ & $\checkmark$ & & & & & & $\checkmark$ & & \\
\hline [20-22] & & & $\checkmark$ & $\checkmark$ & & & $\checkmark$ & & & & & \\
\hline [23] & & $\checkmark$ & & & $\checkmark$ & & $\checkmark$ & & & & & \\
\hline [24] & $\checkmark$ & & & & & & $\checkmark$ & & $\checkmark$ & & & \\
\hline [25] & $\checkmark$ & $\checkmark$ & $\checkmark$ & $\checkmark$ & $\checkmark$ & $\checkmark$ & $\checkmark$ & & $\checkmark$ & $\checkmark$ & & $\checkmark$ \\
\hline [27] & & & $\checkmark$ & & & & $\checkmark$ & & $\checkmark$ & & $\checkmark$ & $\checkmark$ \\
\hline$[30,31]$ & & & $\checkmark$ & & $\checkmark$ & & $\checkmark$ & $\checkmark$ & & & & \\
\hline$[36,37]$ & & & & $\checkmark$ & & & & & $\checkmark$ & $\checkmark$ & & $\checkmark$ \\
\hline [38] & & $\checkmark$ & & $\checkmark$ & & $\checkmark$ & $\checkmark$ & & $\checkmark$ & $\checkmark$ & $\checkmark$ & \\
\hline [39-42] & & $\checkmark$ & & & $\checkmark$ & & & & $\checkmark$ & $\checkmark$ & $\checkmark$ & $\checkmark$ \\
\hline [47-49] & & & $\checkmark$ & $\checkmark$ & & & $\checkmark$ & & $\checkmark$ & $\checkmark$ & $\checkmark$ & \\
\hline [59] & & $\checkmark$ & $\checkmark$ & $\checkmark$ & & $\checkmark$ & $\checkmark$ & $\checkmark$ & & & & $\checkmark$ \\
\hline [60] & & & $\checkmark$ & & & & $\checkmark$ & $\checkmark$ & & & & $\checkmark$ \\
\hline [61] & & & & $\checkmark$ & $\checkmark$ & $\checkmark$ & & $\checkmark$ & & & & $\checkmark$ \\
\hline [62] & $\checkmark$ & $\checkmark$ & $\checkmark$ & & $\checkmark$ & & $\checkmark$ & $\checkmark$ & $\checkmark$ & $\checkmark$ & $\checkmark$ & $\checkmark$ \\
\hline [63] & $\checkmark$ & $\checkmark$ & $\checkmark$ & $\checkmark$ & & & $\checkmark$ & & $\checkmark$ & & & \\
\hline [64] & & $\checkmark$ & $\checkmark$ & & $\checkmark$ & & $\checkmark$ & & $\checkmark$ & $\checkmark$ & & \\
\hline [65] & & & & $\checkmark$ & & $\checkmark$ & & $\checkmark$ & & & & $\checkmark$ \\
\hline [66] & $\checkmark$ & $\checkmark$ & & & $\checkmark$ & & & $\checkmark$ & $\checkmark$ & & & \\
\hline Score & 8 & 12 & 15 & 13 & 11 & 8 & 15 & 11 & 11 & 9 & 5 & 10 \\
\hline$\%$ & 32 & 48 & 60 & 52 & 44 & 32 & 60 & 44 & 44 & 36 & 20 & 40 \\
\hline
\end{tabular}

\subsubsection{Distribution by Methodology Type}

Fig. 7 illustrates the various methodologies used in the articles considered herein. The most common approach was a case study and questionnaire, which featured in $71 \%$ of articles. While $12 \%$ of articles opted for the survey as an approach to optimize the study's subject, flowed by $10 \%$ of articles used the literature review and 7\% are other articles that did not fall under earlier classifications that had been used various methodologies. According to these statistics, case studies and questionnaires are considered the leading and best methodologies for this type of studies. 


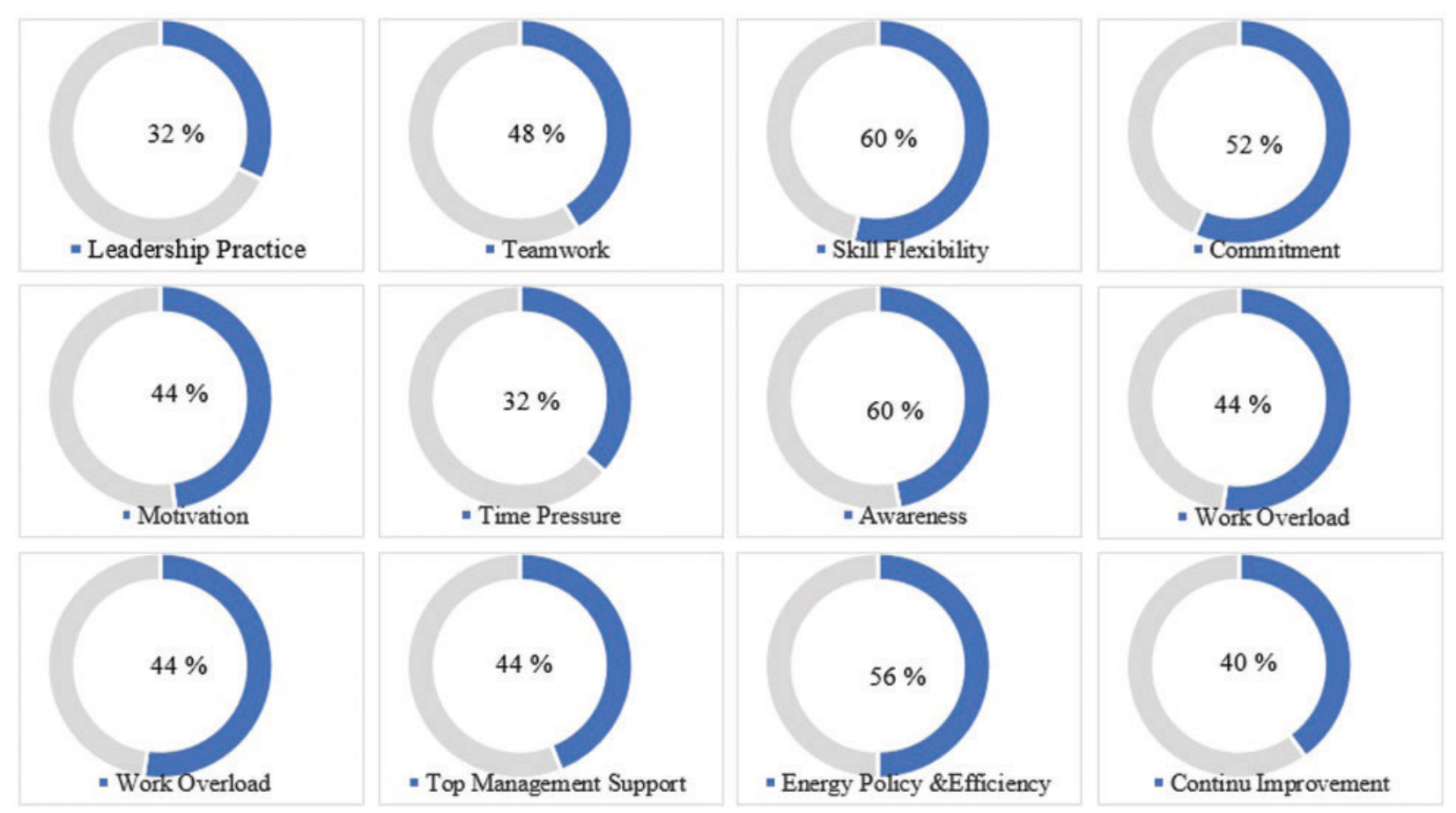

Figure 4: Effect of various indicators of success

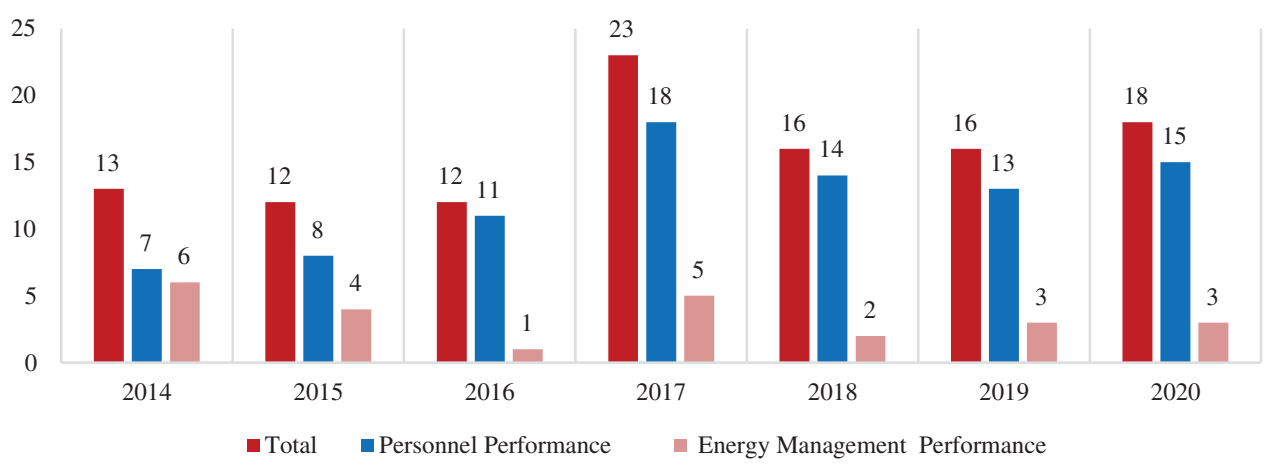

Figure 5: Statistics of articles by publication year

\subsection{Discussion of SLR}

The literature review focused on the current state-of-the-art in the maintenance of power plants by examining the interaction between personnel and energy management performance. By categorizing the literature, readers will be able to understand the topic in an organized manner. For instance, in terms of performance architecture, it is clear that researchers are inclined to propose human performance developments in nuclear power plants, with relatively few applications to other power plants. Some researchers have focused on applications reported in multiple articles, such as Bayesian networks and fuzzy systems, but have paid little attention to social factors 
affecting workers. There has been very little focus on CSFs for either personnel performance and CSFs for energy management with quality energy management in thermal and gas power plants. The SLR highlighted the performance aspects in maintenance that have not received sufficient attention in the previous literature. There is a dearth of information on performance in power plants (thermal and gas) and the critical need to identify relevant CSFs. Analysis of the literature has shown that further investigations are needed to develop the interaction between performance-shaping factors and energy management in power plants so as to minimize human errors.
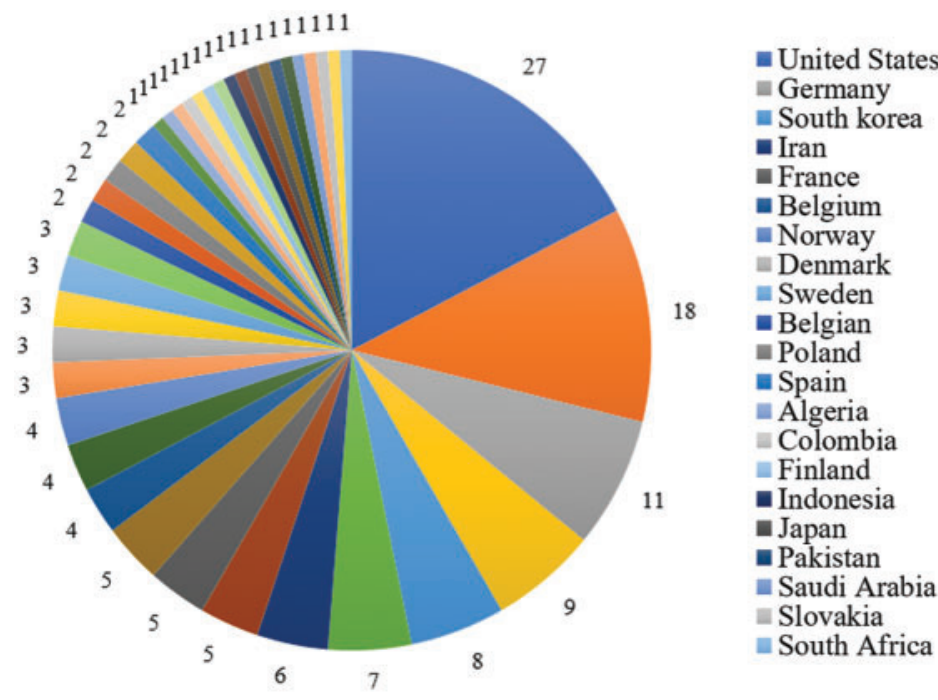

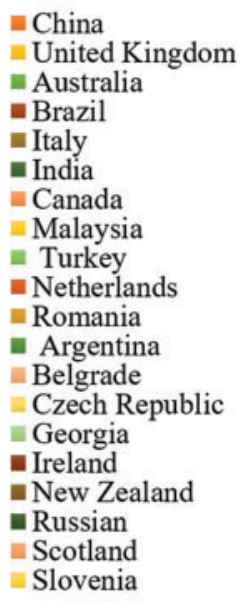

Figure 6: Statistics of articles by authors' nationality

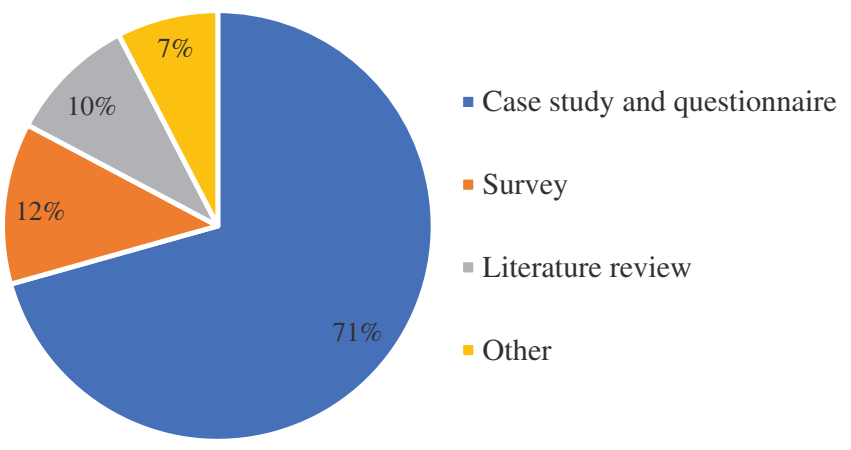

Figure 7: Methodologies applied in the articles

\subsection{Current Challenges}

Analysis of the previous literature indicates a lack of identification of the CSFs for the integration of performance-improving factors with energy management in power plants. Poor performance is not confined to a specific country, but is a complex problem facing most power plants, especially thermal and gas power plants. Rigorous formulations of error, such as by the 
mean squared error (MSE), will help reduce the incidence of human errors $[67,68]$. The literature survey confirmed that human errors in power plant maintenance have increased due to the weak development of performance-shaping factors and the lack of adoption of AI applications. Based on the literature survey, we can summarize some important open issues and challenges that need further investigations:

(i) Weak interest in improving performance through Industry 4.0 has created a workplace environment in which human errors in power plant maintenance have increased.

(ii) There is a lack of comprehensive studies on the integration of personnel performance and energy management performance to improve performance energy management and personnel in gas and thermal power plants.

(iii) No worthwhile studies have addressed the integration of CSFs for personnel and energy management performance, and there is no conceptual framework for optimizing personnel and energy management performance in Iraqi power plants.

(iv) Power plants are suffering from neglect in their maintenance culture, particularly in leadership practices and style as a mediator or moderator.

(v) The lack of studies that identified the CSFs to the success ISO 50001 energy management program in power plants, which seeks to integrate the CSFs associated with energy management and quality management.

(vi) No previous studies have integrated the CSFs associated with energy management and the CSFs associated with quality management to success energy management in the power plant . Doing so would enable the optimization of performance and energy management in one intelligent system, with the leadership or organizational culture used as a mediator or moderator for improving overall performance.

Neglecting to improve these factors leads to an increase in delays in maintenance, Losses in costs and time, accidents, increased failures, losses in electricity production, poor reliability, and energy management weakness.

\subsection{Artificial Intelligence and Performance Improvement in Industry 4.0}

AI can help systems to correctly interpret and utilize data for continuous improvement [69]. In 2012, convolutional neural networks hurried to control on computer research domain and human performance improvement in conjunction with Industry 4.0, and in 2016, the Alpha-Go algorithm was applied to human performance problems in the industry [70]. Regarding the human errors that affect performance-shaping factors, several researchers have suggested methodologies for reducing errors through the concept of AI [71]. The SLR performed in this study has found that AI methodologies have the potential to integrate personnel performance and energy management performance in power plants. However, an intelligent model that can improve performance is still required.

\section{Development of an Intelligent Integrated Framework}

We now propose an intelligent framework for the integration of performance in power plants based on Industry 4.0. An integrated management system IMS will allow groups of different processes and systems to be combined in one intelligent model for continuous improvement, enabling organizations to achieve their goals [72,73]. The integration between CSFs for personnel performance management and energy management helps the power plants to reduce human errors and improve human factors in maintaining power plants. Presenting with research gaps and open 
issues identified, there is an urgent need to develop a conceptual framework to improve overall performance and promote positive interaction between personnel performance and energy management performance in ergonomics power plant maintenance. The performance success indicators identified by this study are used to develop ten hypotheses. The obsolescence of power plants, the apparent weak performance in the electricity sector, was the main reason that encouraged researchers to choose a power plant in Iraq as a model for predicting performance and applying the systematic review results. So, it is considered a good research environment. The researchers took advantage of the comments of the energy experts working in that power plant to consolidate the proposed model by the online meeting. The experts agreed with the analyzed literature on selecting critical success factors to improve performance. This study adopted positivism philosophy and deductive approach. It used the literature to identify theories and variables that the researcher teste using available data. The research object was an Iraqi power plant. A questionnaire consisting of closed questions adopted from [74]. The respondents' sample was who are working in power plant and responses were received July 2021 by Cross-sectional time with simple random sampling techniques. All responses used Likert's Five-Point Scale.

\subsection{Hypothesis Development of Case Study}

To address the research gaps in previous studies, various hypotheses tested the theoretical model for performance improvement. The CSFs that obtained the highest scores in the literature review (see Table and Fig. 8) were adopted, which represents the indicators of CSFs to integration performance for personnel and energy management that includes: skill flexibility (SF) and Awareness (A) by $60 \%$ followed by the energy policy (EP) $56 \%$, commitment (C) $52 \%$, Teamwork (TE) 48\%, work overload (WO) 44\%, top management support (TMS) 44\%, motivation (M) 44\% as the independent variables. Personnel performance (PP) and energy management performance (EMP) are considered as the dependent variables. The purpose of the hypotheses is to verify the reliability with which each factor enhances the integrated performance. The ten research hypotheses are as follows:

H1. Big data for performance through SF has a significant relationship with performance integration.

H2. Big data for performance through A has a significant relationship with performance integration.

H3. Big data for performance through EP has a significant relationship with performance integration.

H4. Big data for performance through $\mathrm{C}$ has a significant relationship with performance integration.

H5. Big data for performance through TE has a significant relationship with performance integration.

H6. Big data for performance through WO has a significant relationship with performance integration.

H7. Big data for performance through TMS has a significant relationship with performance integration. 
H8. Big data for performance through $\mathrm{M}$ has a significant relationship with performance integration.

H9. Intelligent performance integration has a significant relationship with PP.

H10. Intelligent performance integration has a significant relationship with EMP.

Fig. 8 refers to the conceptual model implemented to study the independent variables (IV) that consist of CSFs that derived from the big data for performance with the dependent variable (DV) of intelligent performance integration, which includes PP and EMP in the maintenance of power plants.

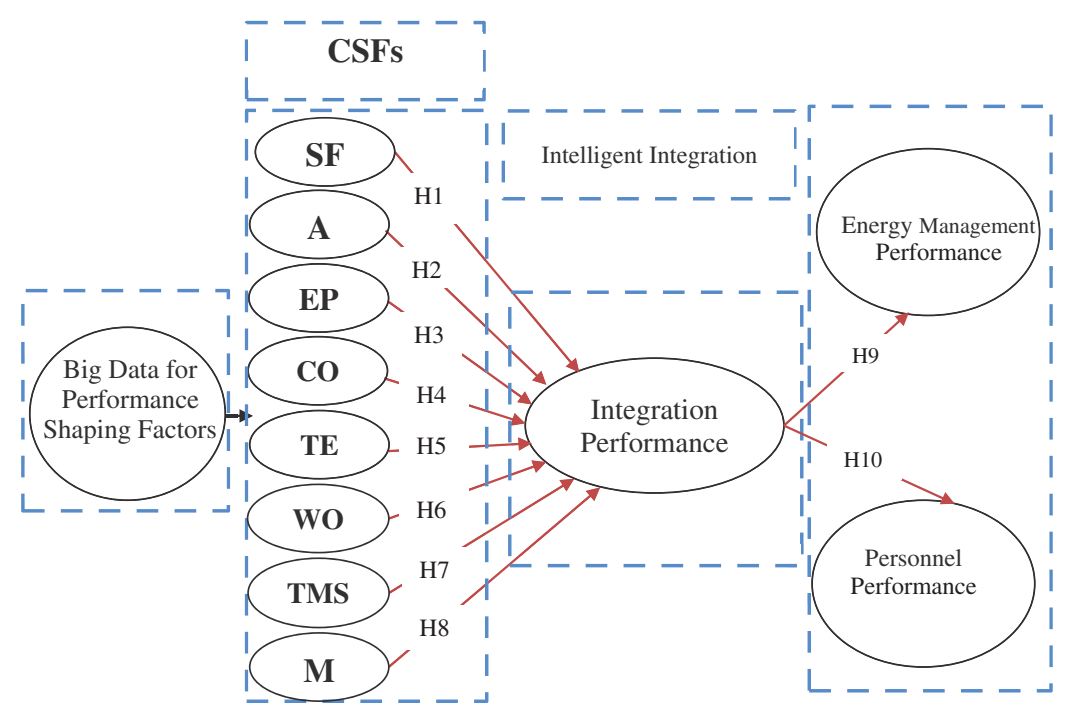

Figure 8: Conceptual integration model for optimizing performance

\subsection{Measurement Model}

Structural equation modeling (SEM) is frequently used for multivariate data analysis [75]. To evaluate the reliability of the proposed model, partial least-squares-based SEM (PLS-SEM) was used within the WarpPLS program which proved successful in this type of studies. Their work was approved in high-ranking journals like [76]. This study analyzed the quality indicators to study the typical suitability of the selected factors and found important, as summarized in Tab. 2. A reliability test and causal assessment recorded scores higher than 0.50 for all variables: SF (0.79), A (0.82), EP (0.91), C (0.87), T (0.76), WO (0.84), TMS (0.78), M (0.79), PP (0.90), EMP (0.89). The analysis results indicate the reliability of the factors and the constructs, as all results were above 0.50 . The results confirm the measurement model proposed acceptable with the Cronbach's alpha values, which should be above 0.50, are as follows: SF (0.75), A (0.79), EP (0.88), C (0.89), $\mathrm{T}(0.80)$, WO (0.81), TMS (0.88), M (0.81), PP (0.91), EMP (0.87). These results indicate that the model is highly reliable and acceptable (see Tab. 3). All hypotheses proposed above were supported and have a significant relationship with performance integration. In particular, we found significant relationships between intelligent performance integration and personnel performance (H9) and between intelligent performance integration and energy management performance (H10). 
Table 2: Indicators of model fit and quality

\begin{tabular}{ll}
\hline Model fit and quality & Indicators \\
\hline Average path coefficient & $=0.554, \mathrm{P}<.001$ \\
Average R-squared & $=0.510, \mathrm{P}<.001$ \\
Sympson's paradox ratio & $=1.010$, accepted when $\geq 0.7$ \\
Statistical suppression ratio & $=1.500$, accepted when $\geq 0.7$ \\
Direction ratio of nonlinear bivariate causality & $=0.943$, accepted when $\geq 0.7$ \\
Average full collinearity & $=3.216$, accepted when $\leq 5$ \\
R-squared contribution ratio & $=1.020$, accepted when $\geq 0.9$ \\
\hline
\end{tabular}

Table 3: Results of hypothesis testing

\begin{tabular}{|c|c|c|c|}
\hline No. & Hypothesis & $\beta$ Value & Results \\
\hline H1 & $\begin{array}{l}\text { Big data for performance through SF has a } \\
\text { significant relationship with integration of } \\
\text { performance }\end{array}$ & $\beta=0.75 \mathrm{p}<.01$ & $\begin{array}{l}\text { Supported \& } \\
\text { significant }\end{array}$ \\
\hline $\mathrm{H} 2$ & $\begin{array}{l}\text { Big data for performance through } \mathrm{A} \text { has a } \\
\text { significant relationship with integration of } \\
\text { performance }\end{array}$ & $\beta=0.79 \mathrm{p}<.01$ & $\begin{array}{l}\text { Supported \& } \\
\text { significant }\end{array}$ \\
\hline H3 & $\begin{array}{l}\text { Big data for performance through EP has a } \\
\text { significant relationship with integration of } \\
\text { performance }\end{array}$ & $\beta=0.88 \mathrm{p}<.01$ & $\begin{array}{l}\text { Supported \& } \\
\text { significant }\end{array}$ \\
\hline $\mathrm{H} 4$ & $\begin{array}{l}\text { Big data for performance through } \mathrm{C} \text { has a } \\
\text { significant relationship with integration of } \\
\text { performance }\end{array}$ & $\beta=0.89 \mathrm{p}<.01$ & $\begin{array}{l}\text { Supported \& } \\
\text { significant }\end{array}$ \\
\hline H5 & $\begin{array}{l}\text { Big data for performance through TE has a } \\
\text { significant relationship with integration of } \\
\text { performance }\end{array}$ & $\beta=0.80 \mathrm{p}<.01$ & $\begin{array}{l}\text { Supported \& } \\
\text { significant }\end{array}$ \\
\hline H6 & $\begin{array}{l}\text { Big data for performance through WO has } \\
\text { a significant relationship with integration of } \\
\text { performance }\end{array}$ & $\beta=0.81 \mathrm{p}<.01$ & $\begin{array}{l}\text { Supported \& } \\
\text { significant }\end{array}$ \\
\hline $\mathrm{H} 7$ & $\begin{array}{l}\text { Big data for performance through TMS has } \\
\text { a significant relationship with integration of } \\
\text { performance }\end{array}$ & $\beta=0.88 \mathrm{p}<.01$ & $\begin{array}{l}\text { Supported \& } \\
\text { significant }\end{array}$ \\
\hline $\mathrm{H} 8$ & $\begin{array}{l}\text { Big data for performance through } \mathrm{M} \text { has a } \\
\text { significant relationship with integration of } \\
\text { performance. }\end{array}$ & $\beta=0.81 \mathrm{p}<.01$ & $\begin{array}{l}\text { Supported \& } \\
\text { significant }\end{array}$ \\
\hline
\end{tabular}


Table 3: Continued

\begin{tabular}{llll}
\hline No. & Hypothesis & $\beta$ Value & Results \\
\hline H9 & $\begin{array}{l}\text { Intelligent performance integration has a } \\
\text { significant relationship with integration of } \\
\text { performance }\end{array}$ & $\beta=0.91 \mathrm{p}<.01$ & $\begin{array}{l}\text { Supported \& } \\
\text { significant }\end{array}$ \\
H10 & $\begin{array}{l}\text { Intelligent performance integration has a } \\
\text { significant relationship with integration of } \\
\text { performance }\end{array}$ & $\beta=0.87 \mathrm{p}<.01$ & $\begin{array}{l}\text { Supported \& } \\
\text { significant }\end{array}$ \\
\hline
\end{tabular}

\section{Conclusion and Recommendation}

The study has investigated the performance shaping factors and energy management in power plants. The results of an SLR and a case study show that poor performance in the maintenance of power plants is largely down to human error. The absence of AI applications and the lack of integration of performance-shaping factors with energy management has contributed to an increase in the occurrence of such errors. This study used the outputs of the SLR analysis to develop an intelligent model for the integration of personnel performance with energy management performance in the maintenance of power plants through a case study conducted in one of the power plants. Analysis using PLS-SEM found that the selected factors were of significant importance to power plant maintenance. A reliability test and causal assessment found that a number of indicators scored higher than 0.50 for reliability, and the proposed measurement model was confirmed to be acceptable according to the Cronbach's alpha reliability coefficient. The case study results confirmed a strong relationship and significance between performance and the identified CSFs. Also confirmed the absence of ISO 5001 energy management programs and quality management programs in the Iraqi power plants. This means the failure of the energy management file and poor performance (personnel and energy management) in the Iraqi maintenance power plants. The research contributions of this study are twofold. First, we have created a coherent taxonomy of research on performance in power plant maintenance, allowing research gaps and current issues to be identified and addressed. Second, the proposed AI model will enable human errors in power plants to be reduced, thus improving the overall maintenance performance. Based on the results of this study, the following recommendations are made:

(i) More research should be conducted on the performance-shaping factors in thermal and gas power plants.

(ii) Applications of AI according to the vision of Industry 4.0 should be investigated in gas and thermal power plants.

(iii) A bi-annual cycle should be used to track motivation and competence levels (qualification and certification), along with maintenance performance results.

(iv) Future studies should focus on maintenance culture, top management support, or leadership practice as a mediator or moderator for enhancing performance.

(v) The CSFs for energy management ISO 50001 should be integrated with quality management to be as an IEQM that include (energy policy, service quality improvement, top management support, awareness, strategic planning, energy management team and energy audit) in power plants, and the organization's culture should be used as a moderator or mediator. 
(vi) Further investigation on the integration the CSFs of PP and EMP represented by teamwork, work overload, time pressure, motivation, commitment, skill flexibility, and top management support should be conducted with the leadership practice as mediator or moderator to improve overall performance and enhance and improve maintenance procedures.

Acknowledgement: Foremost, the authors express their sincere gratitude to Universiti Teknologi Malaysia (UTM)/Razak Faculty of Technology and Informatics for providing financial support. Furthermore, the authors are incredibly grateful to the Iraqi Ministry of Electricity for providing the necessary data.

Funding Statement: This work was supported/funded by the Ministry of Higher Education/University of Technology Malaysia under the Fundamental Research Grant Scheme (FRGS/1/2019/TK08/UTM/02/4).

Conflicts of Interest: The authors declare that they have no conflicts of interest to report regarding the present study.

\section{References}

[1] J. Park, W. Jung and J. Kim, "Inter-relationships between performance shaping factors for human reliability analysis of nuclear power plants," Nuclear Engineering and Technology, vol. 52, no. 1, pp. 87-100, 2020.

[2] T. Yang, L. Zhao and C. Wang, "Review on application of artificial intelligence in power system and integrated energy system," Automation of Electric Power Systems, vol. 43, no. 1, pp. 2-14, 2019.

[3] H. Fatorachian and H. Kazemi, "Impact of industry 4.0 on supply chain performance," Production Planning \& Control, vol. 32, no. 1, pp. 63-81, 2021.

[4] S. Dindar, S. Kaewunruen and M. An, "Bayesian network-based human error reliability assessment of derailments," Reliability Engineering \& System Safety, vol. 197, no. 2, pp. 106825, 2020.

[5] O. Dudnik, M. Vasiljeva, N. Kuznetsov, M. Podzorova, I. Nikolaeva et al., "Trends, impacts, and prospects for implementing artificial intelligence technologies in the energy industry: The implication of open innovation," Journal of Open Innovation: Technology, Market, and Complexity, vol. 7, no. 2, pp. 155, 2021.

[6] E. Y. Iis and A. Thoyib, "The effect of empowerment, work environment, and career development on employees performance with work motivation as the intervening variable in the government of acehIndonesia," Quantitative Economics and Management Studies, vol. 2, no. 6, pp. 376-386, 2021.

[7] N. Kelchevskaya, E. Shirinkina and I. Atlasov, "Assessing energy efficiency factors in industrial companies." Materials Science and Engineering, vol. 862, no. 4, pp. 042001, 2020.

[8] M. Sheikhalishahi, A. Azadeh, L. Pintelon and P. Chemweno, "Human factors effects and analysis in maintenance: A power plant case study," Quality and Reliability Engineering International, vol. 33, no. 4, pp. 895-903, 2017.

[9] R. Peach, H. Ellis and J. Visser, "A maintenance performance measurement framework that includes maintenance human factors: A case study from the electricity transmission industry," South African Journal of Industrial Engineering, vol. 27, no. 2, pp. 177-189, 2016.

[10] J. Brisson, M. Rodriguez, C. A. Martin and R. Proulx, "Plant diversity effect on water quality in wetlands: A meta-analysis based on experimental systems," Ecological Applications, vol. 30, no. 4, pp. 02074, 2020.

[11] H. Diao and M. Ghorbani, "Production risk caused by human factors: A multiple case study of thermal power plants," Frontiers of Business Research in China, vol. 12, no. 1, pp. 15, 2018.

[12] P. Krason, A. Maczewska and A. Polak-Sopinska, "Human factor in maintenance management," Advances in Manufacturing, Production Management and Process Control, vol. 793, no. 3, pp. 49-56, 2018. 
[13] M. Sheikhalishahi, L. Pintelon and A. Azadeh, "An integrated approach for maintenance planning by considering human factors: Application to a petrochemical plant," Process Safety and Environmental Protection, vol. 109, pp. 400-409, 2017.

[14] M. Sheikhalishahi, A. Azadeh and L. Pintelon, "Dynamic maintenance planning approach by considering grouping strategy and human factors," Process Safety \& Environmental Protection, vol. 107, no. 2, pp. 289-298, 2017.

[15] G. Gong, Q. Deng, X. Gong, W. Liu and Q. Ren, "A new double flexible job-shop scheduling problem integrating processing time, green production, and human factor indicators," Journal of Cleaner Production, vol. 174, no. 1, pp. 560-576, 2018.

[16] F. Sgarbossa, E. Grosse, W. Neumann, D. Battini and C. H. Glock, "Human factors in production and logistics systems of the future," Annual Reviews in Control, vol. 49, no. 1, pp. 295-305, 2020.

[17] B. Kadir, O. Broberg and S. Conceição, "Current research and future perspectives on human factors and ergonomics in industry 4.0," Computers \& Industrial Engineering, vol. 137, no. 11, pp. 106004, 2019.

[18] A. Yilmaz, "Strategic approach to managing human factors risk in aircraft maintenance organization: Risk mapping," Aircraft Engineering and Aerospace Technology, vol. 91, no. 4, pp. 654-668, 2019.

[19] F. Sgarbossa, E. Grosse, W. Neumann, D. Battini and H. Glock, "Human factors in production and logistics systems of the future," Annual Reviews in Control, vol. 49, no. 1, pp. 295-305, 2020.

[20] A. Millonig and S. Haustein, "Human factors of digitalized mobility forms and services," European Transport Research Review, vol. 12, no. 1, pp. 46, 2020.

[21] H. Lee and W. Cha, "Virtual reality-based ergonomic modeling and evaluation framework for nuclear power plant operation and control," Sustainability, vol. 11, no. 9, pp. 2630, 2019.

[22] S. Axon, J. Morrissey, R. Aiesha, J. Hillman, A. Revez et al., "The human factor: Classification of european community-based behaviour change initiatives," Journal of Cleaner Production, vol. 182, no. 12, pp. 567-586, 2018.

[23] Y. Bao, C. Guo, J. Zhang, J. Wu, S. Pang et al., "Impact analysis of human factors on power system operation reliability," Journal of Modern Power Systems and Clean Energy, vol. 6, no. 1, pp. 27-39, 2018.

[24] I. Morag, P. Chemweno, L. Pintelon and M. Sheikhalishahi, "Identifying the causes of human error in maintenance work in developing countries," International Journal of Industrial Ergonomics, vol. 68, no. 6, pp. 222-230, 2018.

[25] J. Park, Y. Kim and W. Jung, "Calculating nominal human error probabilities from the operation experience of domestic nuclear power plants," Reliability Engineering \& System Safety, vol. 170, no. 2, pp. 215-225, 2018.

[26] H. Lee, T. Jang and K. Moon, "Anticipating human errors from periodic big survey data in nuclear power plants," IEEE, vol. 1, no. 4, pp. 4777-4778, 2017.

[27] J. Tang, L. Wang, P. Shi, Z. Li, S. Pang et al., "Research on the influence factors system of human error in power system," Advanced Materials Research, vol. 988, no. 2, pp. 687-690, 2014.

[28] M. Liu, P. Tang, P. Liao and L. Xu, "Propagation mechanics from workplace hazards to human errors with dissipative structure theory," Safety Science, vol. 126, no. 6, pp. 104661, 2020.

[29] H. Xu, Y. Lin, X. Zhang and F. Wang, "Power system parameter attack for financial profits in electricity markets," IEEE Transactions on Smart Grid, vol. 11, no. 4, pp. 3438-3446, 2020.

[30] A. Ramezani, T. Nazari, A. Rabiee, K. Hadad and M. Faridafshin, "Human error probability quantification for NPP post-accident analysis using cognitive-based THERP method," Progress in Nuclear Energy, vol. 123, no. 6, pp. 103281, 2020.

[31] W. Preischl and M. Hellmich, "Human error probabilities from operational experience of German nuclear power plants, part II," Reliability Engineering \& System Safety, vol. 148, no. 4, pp. 44-56, 2016.

[32] R. Islam, F. Khan, R. Abbassi and V. Garaniya, "Human error probability assessment during maintenance activities of marine systems," Safety and Health at Work, vol. 9, no. 1, pp. 42-52, 2018.

[33] A. Ramezani, T. Nazari and O. Noori-Kalkhoran, "A proposed improvement for the design of safety injection system in VVER-1000/v446 reactor," Progress in Nuclear Energy, vol. 137, no. 7, pp. 103767, 2021. 
[34] R. Sharma and P. Sharma, "Qualitative and quantitative approaches to analyze reliability of a mechatronic system: A case," Journal of Industrial Engineering International, vol. 11, no. 2, pp. 253-268, 2015.

[35] J. Zhou and Y. Lei, "A slim integrated with empirical study and network analysis for human error assessment in the railway driving process," Reliability Engineering \& System Safety, vol. 204, no. 11, pp. 107148, 2020.

[36] H. Liu, Z. Zhang, T. Zhang and L. Wang, "Revisiting China's provincial energy efficiency and its influencing factors," Energy, vol. 208, no. 3, pp. 118361, 2020.

[37] C. Challis, M. Tierney, A. Todd and E. Wilson, "Human factors in dairy industry process control for energy reduction," Journal of Cleaner Production, vol. 168, no. 8, pp. 1319-1334, 2017.

[38] D. Casado, I. Moschos, O. Kamara, A. Tsolakis, C. Borges et al., "A human-centric context-aware iot framework for enhancing energy efficiency in buildings of public use," IEEE Access, vol. 6, pp. 31444-31456, 2018.

[39] X. Gong, M. Van Wee, T. De Pessemier, S. Verbrugge, D. Colle et al., "Integrating labor awareness to energy-efficient production scheduling under real-time electricity pricing: An empirical study," Journal of Cleaner Production, vol. 168, no. 3, pp. 239-253, 2017.

[40] G. Mert, S. Waltemode and J. C. Aurich, "How services influence the energy efficiency of machine tools: A case study of a machine tool manufacturer," Procedia CIRP, vol. 29, no. 4, pp. 287-292, 2015.

[41] S. Shahzad, J. Brennan, D. Theodossopoulos, B. Hughes and J. K. Calautit, "Energy efficiency and user comfort in the workplace: Norwegian cellular vs. British open plan workplaces," Energy Procedia, vol. 75, no. 2, pp. 807-812, 2015.

[42] C. Hoffmann and K. Thommes, "Can digital feedback increase employee performance and energy efficiency in firms? evidence from a field experiment," Journal of Economic Behavior \& Organization, vol. 180, no. 12, pp. 49-65, 2020.

[43] S. Mahmood, A. Ali, S. Sarip, H. Kaidi, K. Jamaludin et al., "Energy management cultures assessment and its impact on the quality of service in power plants a research gap for future studies," PalArch's Journal of Archaeology of Egypt/Egyptology, vol. 17, no. 7, pp. 11398-11412, 2020.

[44] A. Hilliard, G. Jamieson and D. Jorjani, "Communicating a model-based energy performance indicator," Ergonomics in Design, vol. 22, no. 4, pp. 21-29, 2014.

[45] Z. Irani, A. Sharif and T. Papadopoulos, "Organizational energy: A behavioral analysis of human and organizational factors in manufacturing," IEEE Transactions on Engineering Management, vol. 62, no. 2, pp. 193-204, 2015.

[46] C. Keskin and M. P. Menguc, "On occupant behavior and innovation studies towards high performance buildings: A transdisciplinary approach,” Sustainability, vol. 10, no. 10, pp. 3567, 2018.

[47] W. König, "Energy efficiency in industrial organizations: A cultural-institutional framework of decision making," Energy Research \& Social Science, vol. 60, no. 11, pp. 101314, 2020.

[48] A. Hoang, P. Do and B. Iung, "Energy efficiency performance-based prognostics for aided maintenance decision-making: Application to a manufacturing platform," Journal of Cleaner Production, vol. 142, no. 6, pp. 2838-2857, 2017.

[49] A. Hoang, P. Do and B. Iung, "Investigation on the use of energy efficiency for condition-based maintenance decision-making," IFAC-PapersOnLine, vol. 49, no. 28, pp. 73-78, 2016.

[50] A. Ali, N. Mahmood and S. Kamat, "Thermal comfort at the turbine room in the power station: A systematic review," Journal of Advanced Manufacturing Technology, vol. 10, no. 2, pp. 79-90, 2016.

[51] R. Galvin, "Humans and stuff: Interweaving social and physical science in energy policy research," Energy Research \& Social Science, vol. 26, no. 4, pp. 98-102, 2017.

[52] J. Lopes, R. Kalid, J. Rodríguez and S. Ávila Filho, "A new model for assessing industrial worker behavior regarding energy saving considering the theory of planned behavior, norm activation model and human reliability," Resources, Conservation and Recycling, vol. 145, no. 5, pp. 268-278, 2019.

[53] W. Xu and L. Cao, "Energy efficiency analysis of machine tools with periodic maintenance," International Journal of Production Research, vol. 52, no. 18, pp. 5273-5285, 2014. 
[54] J. Liu and J. Tian, "Traffic management and energy optimization for high-speed trains: An overview of methods for saving energy," IEEE Electrification, vol. 7, no. 3, pp. 66-75, 2019.

[55] A. Karatas, C. Menassa and A. Stoiko, "A framework for delivering targeted occupancy interventions to reduce energy usage in buildings," Procedia Engineering, vol. 118, no. 19, pp. 752-759, 2015.

[56] E. Azar and C. Menassa, "A comprehensive framework to quantify energy savings potential from improved operations of commercial building stocks," Energy Policy, vol. 67, no. 4, pp. 459-472, 2014.

[57] A. Sadiqi, I. Abbassi, A. Barkany, M. Darcherif and A. Biyaali, "A genetic algorithm and B\&B algorithm for integrated production scheduling, preventiveand corrective maintenance to save energy," Management and Production Engineering Review, vol. 11, no. 4, pp. 138-148, 2020.

[58] N. Aughney and G. E. O’Donnell, "The energy saving opportunity in targeting non-value added manufacturing activities a structured approach," Journal of Cleaner Production, vol. 86, no. 2, pp. 191-200, 2015.

[59] F. Sasangohar, S. Peres, J. Williams, A. Smith and M. Mannan, "Investigating written procedures in process safety: Qualitative data analysis of interviews from high-risk facilities," Process Safety and Environmental Protection, vol. 113, no. 1, pp. 30-39, 2018.

[60] K. Park, "Human resource factors associated with workplace safety and health education of small manufacturing businesses in Korea," Journal of Occupational Health, vol. 60, no. 1, pp. 94-101, 2018.

[61] N. A. Stanton and C. Harvey, "Beyond human error taxonomies in assessment of risk in sociotechnical systems: A new paradigm with the EAST 'broken-links' approach," Ergonomics, vol. 60, no. 2, pp. 221-233, 2017.

[62] A. Ahmed, N. Shakir and S. Kamat, "Review and establishing framework model to adoption iso 50001 energy management system in power stations," Journal of Advanced Manufacturing Technology (JAMT), vol. 10, no. 2, pp. 67-78, 2016.

[63] A. Jenko and M. Roblek, "A primary human critical success factors model for the ERP system implementation," Organizacija, vol. 49, no. 3, pp. 145-160, 2016.

[64] Y. Li, H. Song, P. Sang, P. Chen and X. Liu, "Review of critical success factors (CSFs) for green building projects," Building and Environment, vol. 158, no. 32, pp. 182-191, 2019.

[65] N. Mahmood, A. Ajmi, S. Sarip, K. Jamaludin, H. Kaidi et al., "Implications COVID-19 on performance and energy management in the production electricity," Computers, Materials \& Continua, vol. 69, no. 1, pp. 895-911, 2021.

[66] A. Saleh, H. Hashim, M. Awang, A. Zawawi, M. Aswad et al., "A partial least squares structural equation modeling (PLS-SEM) of energy management critical success factors to sustainable university in Malaysia," Journal of Critical Reviews, vol. 7, no. 8, pp. 1330-1338, 2020.

[67] A. S. Ahmar, "Forecast error calculation with mean squared error (MSE) and mean absolute percentage error (MAPE)," JINAV: Journal of Information and Visualization, vol. 1, no. 2, pp. 94-101, 2020.

[68] A. Ahmed, S. Noor, R. Jamaludin, H. Talib, S. Sarip et al., "An efficient framework for identifying current open issues to prevent human errors in maintaining power plants: Research gap," in Materials Today: Proc., India, 2021.

[69] J. Vidovic, "Artificial intelligence: An intelligible future," Cuestiones Politicas, vol. 39, no. 68, pp. 16-20, 2021.

[70] J. Li and D. Liu, "Information bottleneck theory on convolutional neural networks," Neural Processing Letters, vol. 53, no. 2, pp. 1385-1400, 2021.

[71] E. Topol, "High-performance medicine: The convergence of human and artificial intelligence," Nature Medicine, vol. 25, no. 1, pp. 44-56, 2019.

[72] T. Nunhes and J. Oliveira, "Analysis of integrated management systems research: Identifying core themes and trends for future studies," Total Quality Management \& Business Excellence, vol. 31, no. 11-12, pp. 1243-1265, 2020.

[73] A. Handayani and C. Setyatama, "Analysis of supply chain management performance using scor and ahp methods in green avenue apartments of east bekasi," Journal of Applied Science, Engineering, Technology, and Education, vol. 1, no. 2, pp. 141-148, 2019. 
[74] A. Ali, N. Mahmood and S. Kamat, "Increase the performance of power station: Results and analysis of an empirical study of the iso 50001 energy management systems in the Iraqi ministry of electricity," Magnt Research Report, vol. 4, no. 2, pp. 75-86, 2017.

[75] S. P. Derevyanko, "Emotional artificial intelligence in professional training of future psychologists," Information Technologies and Learning Tools, vol. 81, no. 1, pp. 192-209, 2021.

[76] L. Strohm, C. Hehakaya, R. Ranschaert, W. Boon and E. Moors, "Implementation of artificial intelligence (AI) applications in radiology: Hindering and facilitating factors," European Radiology, vol. 30, no. 2, pp. 5525-5532, 2020. 